\title{
Effects of a Four-Week Core Stability Exercise on Functional Movement and Balance in People with Mild Lower-limb Discomfort
}

\author{
Jiyeon $\mathrm{Kim}^{1,2}$, Joungbo Ko${ }^{2}$, Jongil Lim², Hyejung $\mathrm{Choi}^{2}$, Kyoungho Seo ${ }^{2,3}$, Sukho Lee ${ }^{2}$
}

Affiliations: 'University of Houston, Department of Health and Human Performance, Houston, TX, United States, ${ }^{2}$ Texas A\&M University-San Antonio, Department of Counseling, Health and Kinesiology, San Antonio, TX, United States, ${ }^{3}$ Korea University, Department of Physical Education, Seoul, Republic of Korea

Correspondence: S. Lee, Texas A\&M University-San Antonio, Department of Counselling, Health and Kinesiology, One University Way, San Antonio, TX 78224, United States. E-mail: slee@tamusa.edu

ABSTRACT This study aimed to investigate the effects of a short-term core stability exercise on functional movement and balance in people with mild lower-limb discomfort. Twenty people with mild lower-limb discomfort were randomly assigned to control (CG) and core stability exercise training groups (SG, $\mathrm{n}=10$ each). The SG completed twenty 30-min training sessions consisting of Pilates exercises for four weeks. Functional movement, balance, and discomfort level were assessed before and after core stability exercise, using a functional movement test, balance test and visual analogue scale (VAS), respectively. A mixed ANOVA with repeated measures was performed to determine the differences. SG demonstrated a significant increase in hurdle step $(p=0.024$, group $\times$ time effect $)$ and shoulder mobility $(p=0.037$, group $\times$ time effect). The dynamic balance scores were significantly increased from the baseline in both limbs (right, $p=0.007$; left, $p$ $=0.011$, time effect). Post-hoc pairwise comparisons indicated these increases were significant only in SG. Additionally, ankle pain was significantly reduced in $S G(p=0.023$, group $\times$ time effect $)$. This study highlights that four weeks of core stability exercise can positively affect the lower limbs' functional movement and balance in people with mild lower-limb discomfort.

KEY WORDS core stability exercise, balance, functional movement

$@$ MJSSMontenegro

PSYCHOLOGY OF REHABILITATION AND RETURN TO SPORT

http://mjssm.me/?sekcija=article\&artid=198

\section{Introduction}

Insufficient physical activity induced by sedentary lifestyle is one of the critical risk factors in diseases such as cardiovascular diseases, cancer, and diabetes (Bauman \& Owen, 1991; Shephard, 1990; Wang et al., 2019). While proper exercise can reduce the inflammatory response (Beavers et al., 2015), blood pressure (Wong et al., 2018), and the possibility of metabolic disease (Krankel et al., 2019), modern technology has led to decrease in physical activity and an increase a sedentary lifestyle (Church et al., 2011). Studies have reported that people with prolonged, unbroken periods of sitting are more likely to suffer discomforts, such as minor muscle pain, soreness, and stiffness (Søndergaard, Olesen, Søndergaard, De Zee, \& Madeleine, 2010). The persistence of this condition may cause spine dysfunction, resulting in a reduction in the ability of the musculoskeletal system (Marshall \& Gyi, 2010). Given that the human body is a firmly linked chain system across many joints, any misalignment in the system can damage other parts of the body (Rivera, 1994).

Core stability exercise has been widely used to improve activities of daily living and sports while keeping the spine stabilized (Barr, Griggs, \& Cadby, 2007). The core muscles supporting the lumbar-pelvic-hip complex include transverse abdominis, diaphragm, pelvic floor muscles, and deep fibres of the lumbar multifidus. The stabilization of these muscle groups supports the control of trunk motion in all three planes and, therefore, contributes to body stabilization as well as force and power generation in the movement 
(Kibler, Press, \& Sciascia, 2006). The movement in the core stability exercise has its origin in the Pilates exercise programme, which emphasizes inter-segmental coordination of bodily movement. As such, the realignment of the body is promoted in core stability exercise based on the fine and continuous nature of the movement control (Herrington \& Davies, 2005). Furthermore, it has been demonstrated that the effectiveness of core stability exercise in chronic low back pain is facilitated by strengthening the deep spinal muscles (Hodges, 2003).

The previous literature indicated that the core stability exercise had been implemented mainly to characterize the performance enhancement of athletes (Bagherian, Ghasempoor, Rahnama, \& Wikstrom, 2019) and the improvement of balance and functional movement for the elderly people who fall (Granacher, Gollhofer, Hortobagyi, Kressig, \& Muehlbauer, 2013). However, there are a limited number of studies assessing the effect of core stability exercise in healthy adults, rather than in athletes or older populations. Moreover, the intervention period of core stability exercise was relatively long, as was the duration of the training session. These long training schedules may hinder the efficiency of the exercise programme, in particular, not only for those who experience pain or irritation but also for the individuals who are too busy to exercise regularly. A general exercise programme designed for the healthy population might have a negative influence on this population; therefore, special care should be given if people suffer from minor discomfort at the muscular or joint level.

The core stability and its relation to the functional movement have been assessed with a functional movement screen (FMS), which evaluates multi-joint movements related to the core muscle in seven categories (Cook, Burton, Hoogenboom, \& Voight, 2014a). The measurement process focuses on the quantitative and qualitative evaluation of mobility, stability, asymmetry and limitation of the movement. While the test tool has been adopted in many sports for injury prevention and rehabilitation, its limited scoring system might not be sensitive enough to discover the small differences in the effect of the exercise programme. Recently, for the precise assessment of physical balance, studies have attempted to incorporate advanced assessment tools such as balance boards. These measurement systems provide a precise assessment of static as well as dynamic balance control, which may add valuable information in distinguishing the group- or programme-related differences. However, the applicability of the balance board system in examining the relationship between core stability exercise and balance has not been tested yet. Moreover, whether or not the balance board system is sensitive enough to detect the changes in balance that may exist after the core stability exercise intervention for the people with discomfort in the lower extremity remains unclear.

To the best of our knowledge, there have not been any studies using the balance board system and Y-BT in people with discomfort in the lower-limb body. This study aimed to determine the effect of short-term core stability exercise on functional movement and balance in people with mild lower-limb discomfort. It was hypothesized that four weeks of core stability exercise would result in an improvement of functional body movement and balance and could reduce the perceived level of discomfort.

\section{Methods}

\section{Participants}

Twenty volunteers who experience minor lower-limb discomfort were recruited from the Texas A\&M University-San Antonio (TAMUSA) community. Participants were randomly assigned into two groups: control group (CG; $n=10)$ and stability exercise group (SG; $n=10)$ performing a core stability exercise programme. The physical characteristics of the participants are shown in Table 1. Individuals who have been deemed not healthy enough to participate in the study by answering yes to any of the questions on the Physical Activity Readiness Questionnaire (PAR-Q) were excluded. The aim of the study, procedure, benefits, and possible risk factors were explained to the participants. A written consent form approved by the Institutional Review Board was obtained from each participant (IRB \#2017-82).

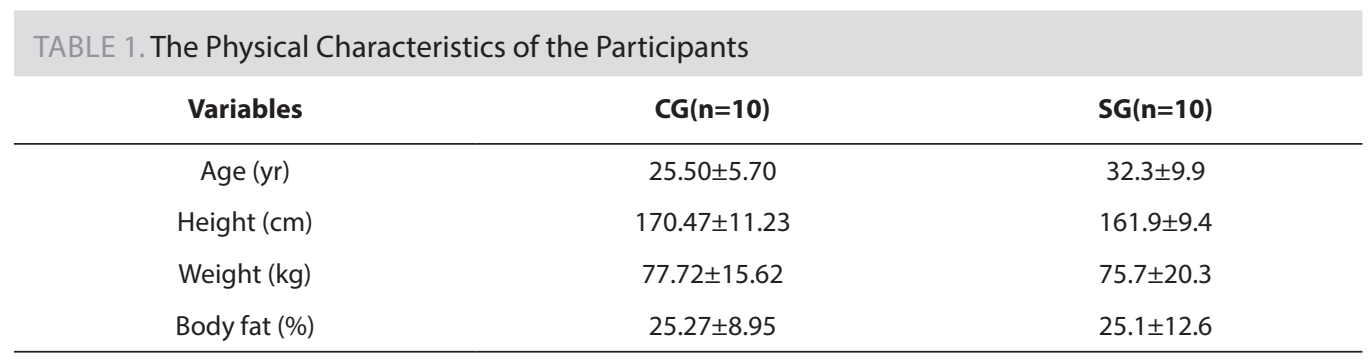

Note. Values are mean \pm SD; BMI: body mass index; CG: control group; SG: stability exercise group.

\section{Core Stability Exercise Programme}

The core stability exercise applied in this study was based on the official programme of the Pilates Academy International-Pilates and Balanced Body University-Pilates methods. The sessions were divided into the following three stages: 1) rolling motion as a general warm-up, 2) core body and limb exercise consisting of eight movements, and 3) stretching exercise as a cool down. A video clip containing the exercise pro- 
gramme was uploaded on YouTube so that participants could easily follow the exercise movements at home by themselves (https://www.youtube.com/watch? $\mathrm{v}=\mathrm{uDjxxJvCd4o}$ ). While CG was asked to maintain their usual lifestyle, SG was required to perform core stability exercise twice a day, three times per week for four weeks until completing a total of twenty sessions. The researchers asked participants to check-in at least once a week for the exercise training at school. Participants were required to bring their training logs. The data from the participants who were not able to complete less than $90 \%$ of the total expected training were excluded from the data analysis in this study.

\section{Measurements}

Anthropometric Measurements

Bodyweight and height were measured using a scale and a wall stadiometer (Novel Products, USA). Body fat percentage was measured with a Biometric device (BX2000, IntelaMetrix, Inc., USA) estimating total body fat from the ultrasound measurements of three standardized body sites of the thigh, abdomen, and chest for male, or thigh, suprailiac, and triceps for female, as described by Jackson and Pollock (Jackson \& Pollock, 1978; Jackson, Pollock, \& Ward, 1980).

\section{Functional Movement Screen (FMS)}

Functional movements were assessed through seven movements (deep squat, hurdle step, in-line lunge, shoulder mobility, active straight leg raise, trunk stability push-up, and rotary stability) using an FMS test kit (Professional FMS Test Kit, FMS Inc., USA). Detailed instruction and scoring procedures are addressed in the previous study (Cook et al., 2014a, 2014b). Two experienced independent raters evaluated each movement pattern for three trials, and the highest score was used to evaluate the lateral symmetry of the movement further.

\section{Balance}

The balance was tested by using a YBT kit (Y-balance Test Kit, FMS Inc., USA), which examined the maximum lower extremity reach of the free leg in the anterior, posteromedial, and posterolateral directions

\begin{tabular}{|c|c|c|c|c|c|c|}
\hline $\begin{array}{c}\text { Variables } \\
\text { (score) }\end{array}$ & Group & Before & After & Source & $\boldsymbol{F}$ & $p$ \\
\hline \multirow{3}{*}{ Deep squat } & CG & $2.5 \pm 0.5$ & $2.6 \pm 0.5$ & Group & 0.375 & 0.555 \\
\hline & \multirow[b]{2}{*}{ SG } & \multirow[b]{2}{*}{$2.4 \pm 0.5$} & \multirow[b]{2}{*}{$2.9 \pm 0.3$} & Time & 5.063 & 0.051 \\
\hline & & & & $\mathrm{G} \times \mathrm{T}$ & 3.273 & 0.104 \\
\hline \multirow{3}{*}{ Hurdle step } & CG & $2.1 \pm 0.3$ & $2.0 \pm 0.5$ & Group & 1.000 & 0.343 \\
\hline & \multirow[b]{2}{*}{ SG } & \multirow[b]{2}{*}{$2.0 \pm 0.5$} & \multirow[b]{2}{*}{$2.5 \pm 0.5^{*}$} & Time & 2.250 & 0.168 \\
\hline & & & & $G \times T$ & 7.364 & 0.024 \\
\hline \multirow{3}{*}{ In-line lunge } & CG & $2.4 \pm 0.8$ & $2.6 \pm 0.7$ & Group & 0.031 & 0.864 \\
\hline & \multirow[b]{2}{*}{ SG } & \multirow[b]{2}{*}{$2.2 \pm 0.9$} & \multirow[b]{2}{*}{$2.7 \pm 0.5$} & Time & 3.645 & 0.089 \\
\hline & & & & $\mathrm{G} \times \mathrm{T}$ & 1.000 & 0.343 \\
\hline \multirow{3}{*}{ Shoulder mobility } & CG & $2.3 \pm 0.5$ & $2.0 \pm 0.7$ & Group & 0.153 & 0.705 \\
\hline & \multirow[b]{2}{*}{ SG } & \multirow[b]{2}{*}{$2.0 \pm 0.8$} & \multirow[b]{2}{*}{$2.1 \pm 0.7$} & Time & 1.000 & 0.343 \\
\hline & & & & $\mathrm{G} \times \mathrm{T}$ & 6.000 & 0.037 \\
\hline \multirow{3}{*}{ Active straight } & CG & $1.9 \pm 0.9$ & $2.1 \pm 0.9$ & Group & 0.375 & 0.555 \\
\hline & \multirow[b]{2}{*}{ SG } & \multirow[b]{2}{*}{$1.9 \pm 0.9$} & \multirow[b]{2}{*}{$2.5 \pm 0.5$} & Time & 6.000 & 0.037 \\
\hline & & & & $\mathrm{G} \times \mathrm{T}$ & 1.000 & 0.343 \\
\hline \multirow{3}{*}{ Trunk stability } & CG & $1.8 \pm 0.9$ & $2.6 \pm 0.7^{*}$ & Group & 0.698 & 0.425 \\
\hline & \multirow[b]{2}{*}{ SG } & \multirow[b]{2}{*}{$2.4 \pm 1.1$} & \multirow[b]{2}{*}{$2.6 \pm 0.7$} & Time & 7.500 & 0.023 \\
\hline & & & & $G \times T$ & 5.063 & 0.051 \\
\hline \multirow{3}{*}{ Rotary stability } & CG & $1.9 \pm 0.3$ & $2.0 \pm 0.5$ & Group & 0.083 & 0.780 \\
\hline & \multirow[b]{2}{*}{ SG } & \multirow[b]{2}{*}{$1.7 \pm 0.7$} & \multirow[b]{2}{*}{$2.1 \pm 0.3$} & Time & 5.000 & 0.052 \\
\hline & & & & $\mathrm{G} \times \mathrm{T}$ & 0.802 & 0.394 \\
\hline \multirow{3}{*}{ Total } & CG & $14.9 \pm 2.8$ & $15.9 \pm 2.8$ & Group & 0.217 & 0.653 \\
\hline & \multirow[b]{2}{*}{ SG } & \multirow[b]{2}{*}{$14.6 \pm 3.9$} & \multirow{2}{*}{$17.4 \pm 1.9^{*}$} & Time & 7.754 & 0.021 \\
\hline & & & & $G \times T$ & 3.050 & 0.115 \\
\hline
\end{tabular}

Note. Value are mean \pm SD; CG: control group; SG: stability exercise group; GXT: group-by-time interaction; *Significant difference compared with before $(p<0.05)$. 
while participants maintain a unilateral stance with the opposite leg centred on a platform. Three trials were performed for each direction. The participant's lower-limb reach was normalized to leg length. Composite reach distance is calculated using the formula: the sum of the three reach directions divided by three times the lower-limb length, multiplied by 100 (Park, 2016).

The HUMAC Balance System (HUMAC Balance, CSMi, USA) was used to measure the movement characteristics. This test compares participant's scores with normative data of their age (Girardi, Konrad, Amin, \& Hughes, 2001). It provides visuals and numerical data of the path they travelled while attempting to maintain balance on different surfaces. The stability score is calculated as follows: "(S standard - A max)/S standard", where "A max" is the axis of maximum sway inches as determined at the $95 \%$ confidence interval. Participants performed for static balance tests and two dynamic balance tests, respectively. For static balance measurements, participants were instructed to maintain their balance for 30 seconds in each of four conditions: 1) with their eyes open while focusing on a red dot on the wall in $1.5 \mathrm{~m}$ distance at eye height while standing on a firm surface (EOFS); 2) with their eyes closed on a firm surface (ECFS); 3) with their eyes open on a soft surface (EOSS); 4) with their eyes closed on a soft surface (ECSS). For the dynamic balance measurements, participants performed five sets of squat exercises for 15 seconds in two different types of surfaces (firm; SF and soft; SS) at $45 \mathrm{bpm}$.

\section{Muscle Strength}

Isometric knee extensor and flexor strength were measured with a hand-held dynamometer (Model 01165, Lafayette, USA). Participants are seated on a chair with the knee flexed to 90 degrees. The peak force in Newton $(\mathrm{N})$ was measured during knee flexion and extension. Two trials were performed for both sides of limbs in two directions with a 60 seconds rest interval between the trials. Whole-body strength was measured with a back body dynamometer (NexGen Ergonomics, USA).

\begin{tabular}{|c|c|c|c|c|c|c|c|}
\hline & $\begin{array}{l}\text { Variables } \\
\text { (score) }\end{array}$ & Group & Before & After & Source & $F$ & $p$ \\
\hline \multirow{6}{*}{$\begin{array}{l}\stackrel{\Xi}{0} \\
\frac{C}{0} \\
\frac{\pi}{\pi} \\
\frac{0}{i}\end{array}$} & \multirow{3}{*}{ Right } & CG & $83.1 \pm 10.9$ & $84.8 \pm 12.5$ & Group & 0.145 & 0.712 \\
\hline & & \multirow[b]{2}{*}{ SG } & \multirow[b]{2}{*}{$79.0 \pm 8.5$} & \multirow[b]{2}{*}{$85.1 \pm 7.0^{*}$} & Time & 11.870 & 0.007 \\
\hline & & & & & GXT & 2.065 & 0.185 \\
\hline & \multirow{3}{*}{ Left } & CG & $83.1 \pm 9.7$ & $84.1 \pm 11.4$ & \multirow{3}{*}{$\begin{array}{l}\text { Group } \\
\text { Time } \\
\text { G×T }\end{array}$} & 0.202 & 0.663 \\
\hline & & & & & & 10.216 & 0.011 \\
\hline & & SG & $78.4 \pm 7.7$ & $84.7 \pm 6.1^{*}$ & & 2.611 & 0.141 \\
\hline \multirow{12}{*}{ 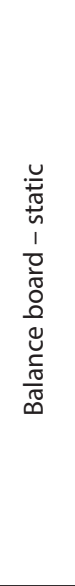 } & \multirow{3}{*}{$\begin{array}{l}\text { Eye Open } \\
\text { Firm Surface }\end{array}$} & CG & $91.8 \pm 2.4$ & $91.9 \pm 2.3$ & \multirow{3}{*}{$\begin{array}{c}\text { Group } \\
\text { Time } \\
\text { GXT }\end{array}$} & 0.364 & 0.561 \\
\hline & & & & & & 0.096 & 0.764 \\
\hline & & SG & $90.8 \pm 3.0$ & $91.3 \pm 4.3$ & & 0.109 & 0.749 \\
\hline & \multirow{3}{*}{$\begin{array}{l}\text { Eye Close } \\
\text { Firm Surface }\end{array}$} & CG & $91.8 \pm 2.3$ & $90.4 \pm 3.6^{*}$ & \multirow{3}{*}{$\begin{array}{l}\text { Group } \\
\text { Time } \\
\text { G×T }\end{array}$} & 0.441 & 0.523 \\
\hline & & & & & & 5.062 & 0.051 \\
\hline & & SG & $92.3 \pm 2.3$ & $91.3 \pm 3.1$ & & 0.101 & 0.758 \\
\hline & \multirow{3}{*}{$\begin{array}{l}\text { Eye Open } \\
\text { Soft Surface }\end{array}$} & CG & $86.7 \pm 3.3$ & $83.8 \pm 3.4^{*}$ & \multirow{3}{*}{$\begin{array}{c}\text { Group } \\
\text { Time } \\
\text { GXT }\end{array}$} & 0.227 & 0.645 \\
\hline & & & & & & 14.548 & 0.004 \\
\hline & & SG & $85.5 \pm 4.3$ & $83.0 \pm 5.8$ & & 0.039 & 0.847 \\
\hline & \multirow{3}{*}{$\begin{array}{l}\text { Eye Close } \\
\text { Soft Surface }\end{array}$} & CG & $77.5 \pm 6.2$ & $75.8 \pm 5.3$ & \multirow{3}{*}{$\begin{array}{l}\text { Group } \\
\text { Time } \\
\text { GXT }\end{array}$} & 0.340 & 0.574 \\
\hline & & & & & & 0.163 & 0.696 \\
\hline & & SG & $73.4 \pm 9.7$ & $76.2 \pm 7.6$ & & 6.544 & 0.031 \\
\hline \multirow{6}{*}{ 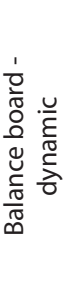 } & \multirow{3}{*}{$\begin{array}{c}\text { Squat } \\
\text { Firm Surface }\end{array}$} & CG & $67.9 \pm 7.9$ & $63.7 \pm 10.8$ & \multirow{3}{*}{$\begin{array}{c}\text { Group } \\
\text { Time } \\
\text { GXT }\end{array}$} & 3.584 & 0.091 \\
\hline & & & & & & 1.077 & 0.326 \\
\hline & & SG & $51.7 \pm 25.2$ & $62.9 \pm 10.0$ & & 4.572 & 0.061 \\
\hline & \multirow{3}{*}{$\begin{array}{c}\text { Squat } \\
\text { Soft Surface }\end{array}$} & CG & $62.1 \pm 12.7$ & $58.8 \pm 7.7$ & \multirow{3}{*}{$\begin{array}{c}\text { Group } \\
\text { Time } \\
\text { GXT }\end{array}$} & 2.921 & 0.122 \\
\hline & & & & & & 0.932 & 0.360 \\
\hline & & SG & $46.0 \pm 19.8$ & $55.6 \pm 13.7$ & & 7.353 & 0.024 \\
\hline
\end{tabular}

Note. Value are mean \pm SD; CG: control group; SG: stability exercise group; GXT: group-by-time interaction; ${ }^{*}$ Significant difference compared with before $(p<0.05)$.

\section{Discomfort}

We assessed the degree of discomfort using the Visual Analogue Scale (VAS). The degree of discomfort in each body site was expressed as a number between 1 and $10 \mathrm{~cm}$. 


\section{Statistical analysis}

All outcome variables were averaged across the trials repeated within each assessment condition. A mixed ANOVA with repeated measures was performed to determine the between (CG and SG) and within (pre- and post-intervention) group differences. In the case of violations of the sphericity assumption, F-values were adjusted with the Greenhouse-Geisser procedure. Significant interaction effects were further analysed using pairwise comparisons ( $t$-tests). All tests were conducted at $\alpha=0.05$ and performed using SPSS 19.0 (IBM, Armonk, NY, USA).

\section{Results}

\section{Functional Movement Screen}

Descriptive statistics of the effects of the four-week core stability exercise on FMS are presented in Table 2. A significant group-by-time interaction was observed in hurdle step and shoulder mobility $(\mathrm{p}<.05)$. Post-hoc analysis indicated that while SG did improve the score of hurdle step after a four-week core stability exercise intervention, the shoulder mobility score did not change significantly in SG. There was a significant main effect of time on active straight, trunk stability, and total FMS score $(\mathrm{p}<.05)$. Only SG showed a significant increase in the total FMS score $(\mathrm{p}<.05)$.

\section{Balance}

The effects of core stability exercise on balance measures are presented in Table 3. There was no significant group-by-time interaction for any of the variables in the Y-balance test. However, a significant main effect of time on both right $(\mathrm{p}<.01)$ and left $(\mathrm{p}<.05)$ limb, post-hoc pairwise comparisons indicated a significant increase in the balance of both limbs only in $S G(p<.05)$.

The results of static and dynamic balance measured with the balance board showed significant interaction effect between group and time in both static (ECSS) and dynamic (SS) balance performed on the soft surface $(\mathrm{p}<.05)$. There was a significant main effect of time in EOSS $(\mathrm{p}<.01)$, and a comparison between pre- and post-intervention indicated a significant decrease in stability score in CG $(\mathrm{p}<.05)$, whereas SG exhibited a similar static balance control.

\section{Muscle Strength}

Lower-limb and whole-body muscle strength did not change significantly for both groups (Table 4). While a significant main effect of time on right leg flexion was detected, post hoc comparisons failed to show the difference between pre- and post-intervention for both groups.

\begin{tabular}{|c|c|c|c|c|c|c|}
\hline $\begin{array}{c}\text { Variables } \\
(\mathbf{k g})\end{array}$ & Group & Before & After & Source & $F$ & $p$ \\
\hline \multirow{3}{*}{$\begin{array}{l}\text { Right Leg } \\
\text { Extension } \\
\text { (RLE) }\end{array}$} & CG & $40.7 \pm 12.6$ & $38.1 \pm 12.3$ & \multirow{3}{*}{$\begin{array}{l}\text { Group } \\
\text { Time } \\
\text { GxT }\end{array}$} & 0.039 & 0.848 \\
\hline & & & & & 1.907 & 0.201 \\
\hline & SG & $32.5 \pm 15.5$ & $36.4 \pm 16.7$ & & 0.003 & 0.955 \\
\hline \multirow{3}{*}{$\begin{array}{l}\text { Right Leg } \\
\text { Flexion } \\
\text { (RLF) }\end{array}$} & CG & $25.2 \pm 8.0$ & $27.1 \pm 8.4$ & \multirow{3}{*}{$\begin{array}{l}\text { Group } \\
\text { Time } \\
\text { GXT }\end{array}$} & 0.935 & 0.359 \\
\hline & & & & & 11.317 & 0.008 \\
\hline & SG & $25.4 \pm 4.8$ & $26.6 \pm 10.6$ & & 0.005 & 0.946 \\
\hline \multirow{3}{*}{$\begin{array}{l}\text { Left Leg } \\
\text { Extension } \\
\text { (LLE) }\end{array}$} & CG & $33.4 \pm 9.3$ & $35.9 \pm 6.2$ & \multirow{3}{*}{$\begin{array}{l}\text { Group } \\
\text { Time } \\
\text { G×T }\end{array}$} & 0.746 & 0.410 \\
\hline & & & & & 0.081 & 0.782 \\
\hline & SG & $34.2 \pm 12.9$ & $36.5 \pm 14.7$ & & 2.774 & 0.130 \\
\hline \multirow{3}{*}{$\begin{array}{l}\text { Left Leg } \\
\text { Flexion } \\
\text { (LLF) }\end{array}$} & CG & $24.7 \pm 5.8$ & $28.1 \pm 5.9$ & \multirow{3}{*}{$\begin{array}{l}\text { Group } \\
\text { Time } \\
\text { GxT }\end{array}$} & 0.002 & 0.963 \\
\hline & & & & & 1.120 & 0.317 \\
\hline & SG & $22.9 \pm 5.0$ & $26.1 \pm 8.8$ & & 0.033 & 0.861 \\
\hline \multirow{3}{*}{$\begin{array}{l}\text { Whole body } \\
\text { muscle } \\
\text { strength }\end{array}$} & CG & $255.8 \pm 91.8$ & $258.0 \pm 92.6$ & \multirow{3}{*}{$\begin{array}{l}\text { Group } \\
\text { Time } \\
\text { GxT }\end{array}$} & 1.358 & 0.274 \\
\hline & & & & & 4.646 & 0.059 \\
\hline & SG & $191.9 \pm 81.2$ & $235.8 \pm 82.6$ & & 2.403 & 0.156 \\
\hline
\end{tabular}

Note. Value are mean \pm SD; CG: control group; SG: stability exercise group; GXT: group-by-time interaction.

\section{Discomfort}

Table 5 showed the exercise-induced change in VAS. There was a significant interaction between group and time in ankle pain $(\mathrm{p}<.05)$, and the VAS score of ankle pain was significantly reduced in the SG. A significant main effect of time was shown in knee pain, but no significant time-related changes for both groups were detected by post hoc comparisons. 


\begin{tabular}{|c|c|c|c|c|c|c|}
\hline $\begin{array}{c}\text { Variables } \\
(\mathrm{cm})\end{array}$ & Group & Before & After & Source & $F$ & $p$ \\
\hline \multirow{3}{*}{ Body pain } & CG & $1.3 \pm 1.5$ & $0.9 \pm 0.9$ & \multirow{3}{*}{$\begin{array}{c}\text { Group } \\
\text { Time } \\
\text { GXT }\end{array}$} & 0.277 & \multirow{2}{*}{$\begin{array}{l}0.611 \\
0.090\end{array}$} \\
\hline & & & & & 3.608 & \\
\hline & SG & $1.9 \pm 1.8$ & $1.2 \pm 1.8$ & & 0.123 & 0.734 \\
\hline \multirow{3}{*}{ Exercise pain } & CG & $2.2 \pm 1.9$ & $1.6 \pm 1.5$ & \multirow{3}{*}{$\begin{array}{c}\text { Group } \\
\text { Time } \\
\text { GXT }\end{array}$} & 0.000 & \multirow{3}{*}{$\begin{array}{l}0.988 \\
0.134 \\
0.876\end{array}$} \\
\hline & & & & & 2.709 & \\
\hline & SG & $2.1 \pm 2.2$ & $1.7 \pm 1.9$ & & 0.026 & \\
\hline \multirow{3}{*}{ Waist pain } & CG & $2.1 \pm 1.4$ & $2.2 \pm 1.4$ & \multirow{3}{*}{$\begin{array}{c}\text { Group } \\
\text { Time } \\
\text { GXT }\end{array}$} & 1.428 & \multirow{3}{*}{$\begin{array}{l}0.205 \\
0.494 \\
0.324\end{array}$} \\
\hline & & & & & 0.509 & \\
\hline & SG & $1.4 \pm 1.7$ & $1.0 \pm 1.7$ & & 1.09 & \\
\hline \multirow{3}{*}{ Knee pain } & CG & $2.0 \pm 1.7$ & $1.0 \pm 1.2$ & \multirow{3}{*}{$\begin{array}{c}\text { Group } \\
\text { Time } \\
\text { GXT }\end{array}$} & 0.000 & \multirow{2}{*}{0.039} \\
\hline & & & & & 5.791 & \\
\hline & SG & $1.6 \pm 1.8$ & $1.4 \pm 2.1$ & & 2.098 & 0.181 \\
\hline \multirow{3}{*}{ Pelvis pain } & CG & $1.9 \pm 2.1$ & $2.3 \pm 2.2$ & \multirow{3}{*}{$\begin{array}{c}\text { Group } \\
\text { Time } \\
\text { GXT }\end{array}$} & 2.161 & \multirow{2}{*}{$\begin{array}{l}0.176 \\
0.957\end{array}$} \\
\hline & & & & & 0.003 & \\
\hline & SG & $1.0 \pm 1.9$ & $0.6 \pm 0.9$ & & 1.935 & 0.198 \\
\hline \multirow{3}{*}{ Ankle pain } & CG & $1.1 \pm 0.9$ & $1.0 \pm 1.3$ & \multirow{3}{*}{$\begin{array}{c}\text { Group } \\
\text { Time } \\
\text { GXT }\end{array}$} & 0.355 & \multirow{2}{*}{$\begin{array}{l}0.566 \\
0.059\end{array}$} \\
\hline & & & & & 4.683 & \\
\hline & SG & $2.1 \pm 2.2$ & $0.5 \pm 0.9$ & & 7.488 & 0.023 \\
\hline
\end{tabular}

Note. Value are mean $\pm \mathrm{SD}$; CG: control group; SG: stability exercise group; GXT: group-by-time interaction.

\section{Discussion}

The objectives of this study were twofold: (1) to determine the effect of core stability exercise on functional body movements and balance in people with discomfort in their lower limbs, and (2) to assess whether a balance board system can be used in conjunction with Y-balance test in evaluating balance control. Our first hypothesis was partially supported by measures of FMS, balance, and VAS. Our second hypothesis was supported by the increased balance control in both static and dynamic balance conditions and confirmed the validity of using the balance board system in assessing the effects of core stability exercise on balance control.

The hurdle step, shoulder mobility, and FMS total score were significantly increased in SG after the exercise intervention. The successful completion of the hurdle step test without compromising body balance proves that movement functions were improved in a four-week intervention period. It is also likely that the observed increases in shoulder joint mobility are associated with enhanced upper limb function, such as a relaxation of the muscle through the stretching motions in the exercise programme. While the effectiveness of core stability exercise has been addressed across a wide range of groups even including the highly active collegiate athlete (Lasey \& Donne, 2019), these current findings further suggest its applicability to the group experiencing discomfort in their lower limbs. However, it seems premature to generalize the significance of reduced intervention period and duration employed in this study to other contexts.

Balance control ability exhibited a significant improvement after exercise intervention. The YBT outcome indicated that the dynamic balance and functional symmetry were improved so that it reduces their risk of injury. The existing literature indicates that the YBT can evaluate the coordination of the lower-limb body and the dynamic equilibrium ability. Previous studies have used the YBT not only for the healthy adults and adolescents but also for athletes with a sprain or chronic instability in their lower limbs. The measurement reliability of Y-balance was reported to be about 0.82 to 0.87 ; it seems likely that it is sufficient to produce reliable results. However, we also understand that the Y-balance test may not be an ideal test for the participant with minor lower-limb discomfort. While the convenience and reliability of YBT have been demonstrated sufficiently, the measure of static balance provides additional information on the balance control. As expected, the intended use of the balance board system in this study further revealed an improvement in static balance control, which is considered to be controlled independently from the dynamic balance (Rose et al., 2002). However, interestingly, the improvement of both static and dynamic balance in SG exhibited in more challenging conditions, rather than the firm surface. Presumably, the participants' level of discomfort in this study might not be severe enough to interfere with the maintaining of equilibrium while in a stationary position. We did not conduct the reliability and construct validity to test the balance board in this study. Even though the reliability and concurrent validity of the HUMAC Balance System have been tested and verified as moderate to good in previous studies, they can be still considered to be limitations to this the study.

Furthermore, in addition to the study reporting the positive effects of yoga exercise on COP characteristics 
(Jeter, Moonaz, Bittner, \& Dagnelie, 2015), the equivalent results shown in this study emphasized the importance of assessing the static balance in people with dysfunctions in musculoskeletal, somatosensory, and vestibular functions. Given that the traditional COP measure was conducted with a ground-mounted force platform in biomechanical settings and has been used as a surrogate marker for postural stability in standing balance (Piirtola \& Era, 2006), the necessity of using a balance measurement system in exercise intervention protocol becomes greater.

Enhancement of core muscle strength is known to play an essential role in facilitating the dynamic stability of muscles across the segments (Panjabi, 1992). In particular, multifidus and transversus abdominis contract simultaneously to provide dynamic stability to the core muscles, leading to improved posture alignment and functional movement (Vleeming, Schuenke, Danneels, \& Willard, 2014). However, the evaluation of muscle strength did not reach the statistical significance in SG, which suggests that improved functional movement and balance may occur without a substantial increase in muscle strength. A previous study reported that FMS scores of collegiate football players were positively correlated with hopping performance, but were not correlated with hip and knee strength (Willigenburg \& Hewett, 2017). Lastly, although people with mild discomfort in their lower body do not usually require hospital treatment, there might be a need for more organized and specialized exercise programmes with proper intensity and duration for the purpose of injury prevention.

It is essential to mention that SG' VAS for pain was reduced significantly after the exercise intervention. Although the VAS is somewhat subjective and influenced by other contextual factors, it may reflect participants' psychological influence by being more active with the exercise programme. It has been reported that Pilates exercise improved young females' spine and shoulder pain, as well as body instability (Kim, 2017).

In summary, this study has demonstrated that four weeks of core stability exercise was beneficial for reducing the pain and discomfort by increasing the functional movement and balance. Although the sample size was small and may have limited detecting impacts on parameters, there were few studies of exercise programmes for the people with lower-limb discomfort and with a short period of training. Therefore, the authors believe that this study can serve as a positive starting point for making exercise guidelines for those populations. However, further controlled studies with a varied combination of exercise period and frequency are needed to more fully understand the effect of core stability exercise on the quality of life in people with mild pain and discomfort.

\section{References}

Bagherian, S., Ghasempoor, K., Rahnama, N., \& Wikstrom, E. A. (2019). The Effect of Core Stability Training on Functional Movement Patterns in College Athletes. Journal of Sport Rehabilitation, 28(5), 444-449. doi: 10.1123/jsr.2017-0107

Barr, K. P., Griggs, M., \& Cadby, T. (2007). Lumbar stabilization: a review of core concepts and current literature, part 2. American Journal of Physical Medicine \& Rehabilitation, 86(1), 72-80. doi: 10.1097/01. phm.0000250566.44629.a0

Bauman, A., \& Owen, N. (1991). Habitual physical activity and cardiovascular risk factors. Medical Journal of Australia, 154(1), 22-28. doi: 10.5694/j.1326-5377.1991.tb112841.x

Beavers, K. M., Beavers, D. P., Newman, J. J., Anderson, A. M., Loeser, R. F., Jr., Nicklas, B. J., . . Messier, S. P. (2015). Effects of total and regional fat loss on plasma CRP and IL-6 in overweight and obese, older adults with knee osteoarthritis. Osteoarthritis Cartilage, 23(2), 249-256. doi:10.1016/j.joca.2014.11.005

Church, T. S., Thomas, D. M., Tudor-Locke, C., Katzmarzyk, P. T., Earnest, C. P., Rodarte, R. Q., ... Bouchard, C. (2011). Trends over 5 decades in US occupation-related physical activity and their associations with obesity. PloS one, 6(5), e19657. doi:10.1371/journal.pone.0019657

Cook, G., Burton, L., Hoogenboom, B. J., \& Voight, M. (2014a). Functional movement screening: the use of fundamental movements as an assessment of function-part 1. International journal of sports physical therapy, 9(3), 396-409.

Cook, G., Burton, L., Hoogenboom, B. J., \& Voight, M. (2014b). Functional movement screening: the use of fundamental movements as an assessment of function-part 2. International journal of sports physical therapy, 9(4), 549-563.

DeJong, A. F., Mangum, L. C., \& Hertel, J. (2020). Ultrasound Imaging of the Gluteal Muscles during the Y-Balance Test in Individuals With or Without Chronic Ankle Instability. Journal of Athletic Training, 55(1), 49-5. doi: 10.4085/1062-6050-363-18

Girardi, M., Konrad, H. R., Amin, M., \& Hughes, L. F. (2001). Predicting fall risks in an elderly population: computer dynamic posturography versus electronystagmography test results. The Laryngoscope, 111(9), 1528-1532. doi:10.1097/00005537-200109000-00008

Granacher, U., Gollhofer, A., Hortobagyi, T., Kressig, R. W., \& Muehlbauer, T. (2013). The importance of trunk muscle strength for balance, functional performance, and fall prevention in seniors: a systematic review. Sports medicine, 43(7), 627-641. doi: 10.1007/s40279-013-0041-1

Herrington, L., \& Davies, R. (2005). The influence of Pilates training on the ability to contract the transversus abdominis muscle in asymptomatic individuals. Journal of bodywork and movement therapies, 9(1), 52-57. doi:10.1016/j.jbmt.2003.12.005

Hodges, P. W. (2003). Core stability exercise in chronic low back pain. Orthopedic Clinics, 34(2), 245-254. doi: 10.1016/S0030-5898(03)00003-8 
Jackson, A. S., \& Pollock, M. L. (1978). Generalized equations for predicting body density of men. British journal of nutrition, 40(3), 497-504. doi: 10.1079/BJN19780152

Jackson, A. S., Pollock, M. L., \& Ward, A. (1980). Generalized equations for predicting body density of women. Medicine and science in sports and exercise, 12(3), 175-181.

Jeter, P. E., Moonaz, S. H., Bittner, A. K., \& Dagnelie, G. (2015). Ashtanga-based yoga therapy increases the sensory contribution to postural stability in visually-impaired persons at risk for falls as measured by the wii balance board: a pilot randomized controlled trial. PloS one, 10(6), e0129646. doi: 10.1371/journal. pone. 0129646

Kibler WB, Press J, \& Sciascia A. (2006). The role of core stability in athletic function. Sports Medicine, 36(3) 189-198. doi: 10.2165/00007256-200636030-00001.

Kim, H. (2017). The effect of Pilates springboard exercise on isokinetic muscular strength, functional movement in college-aged women. Unpublished Doctoral Dissertation, Seoul, Republic of Korea: Dongduk women's University.

Krankel, N., Bahls, M., Van Craenenbroeck, E. M., Adams, V., Serratosa, L., Solberg, E. E., . . Kemps, H. (2019). Exercise training to reduce cardiovascular risk in patients with metabolic syndrome and type 2 diabetes mellitus: How does it work? European Journal of Preventive Cardiology, 26(7), 701-708. doi: $10.1177 / 2047487318805158$

Lacey, M., \& Donne, B. (2019). Does Fatigue Impact Static and Dynamic Balance Variables in Athletes with a Previous Ankle Injury? International Journal of Exercise Science, 12(3), 1121.

Marshall, S., \& Gyi, D. (2010). Evidence of health risks from occupational sitting: where do we stand? American journal of preventive medicine, 39(4), 389-391. doi: 10.1016/j.amepre.2010.07.001

Plisky, P. J., Gorman, P. P., Butler, R. J., Kiesel, K. B., Underwood, F. B., \& Elkins, B. (2009). The reliability of an instrumented device for measuring components of the star excursion balance test. North American journal of sports physical therapy, 4(2), 92.

Panjabi, M. M. (1992). The stabilizing system of the spine. Part I. Function, dysfunction, adaptation, and enhancement. Journal of spinal disorders, 5, 383-383. doi: 10.1097/00002517-199212000-00001

Park, W. Y. (2016). Effects of Complex Neoromuscular Training on Lower Extremity Injury Risk in Freestyle Ski Players. The Korean Society of Living Environmental System, 23(2), 235-242. doi: 10.21086/ ksles.2016.04.23.2.235

Piirtola, M., \& Era, P. (2006). Force platform measurements as predictors of falls among older people-a review. Gerontology, 52(1), 1-16. doi: 10.1159/000089820

Rivera, J. E. (1994). Open versus closed kinetic chain rehabilitation of the lower extremity: a functional and biomechanical analysis. Journal of Sport Rehabilitation, 3(2), 154-167. doi: 10.1123/jsr.3.2.154

Rose, J., Wolff, D. R., Jones, V. K., Bloch, D. A., Oehlert, J. W., \& Gamble, J. G. (2002). Postural balance in children with cerebral palsy. Developmental medicine and child neurology, 44(1), 58-63. doi: 10.1017/ S0012162201001669

Shephard, R. J. (1990). Physical activity and cancer. International Journal of Sports Medicine, 11(6), 413-420. doi:10.1055/s-2007-1024830

Søndergaard, K. H., Olesen, C. G., Søndergaard, E. K., De Zee, M., \& Madeleine, P. (2010). The variability and complexity of sitting postural control are associated with discomfort. Journal of Biomechanics, 43(10), 1997-2001. doi: 10.1016/j.jbiomech.2010.03.009

Vleeming, A., Schuenke, M., Danneels, L., \& Willard, F. (2014). The functional coupling of the deep abdominal and paraspinal muscles: the effects of simulated paraspinal muscle contraction on force transfer to the middle and posterior layer of the thoracolumbar fascia. Journal of anatomy, 225(4), 447-462. doi: 10.1111/ joa. 12227

Wang, Y., Lee, D. C., Brellenthin, A. G., Eijsvogels, T. M. H., Sui, X., Church, T. S., . . Blair, S. N. (2019). Leisure-Time Running Reduces the Risk of Incident Type 2 Diabetes. The American Journal of Medicine. doi:10.1016/j.amjmed.2019.04.035

Willigenburg, N., \& Hewett, T. E. (2017). Performance on the Functional Movement Screen ${ }^{\mathrm{Tw}}$ is related to hop performance, but not to hip and knee strength in collegiate football players. Clinical journal of sport medicine, 27(2), 119. doi: 10.1097/JSM.0000000000000317

Wong, A., Kwak, Y. S., Scott, S. D., Pekas, E. J., Son, W. M., Kim, J. S., \& Park, S. Y. (2018). The effects of swimming training on arterial function, muscular strength, and cardiorespiratory capacity in postmenopausal women with stage 2 hypertension. Menopause, 26(6), 653-658. doi:10.1097/GME.0000000000001288 